\title{
A review on dietary fiber in cereals and its characterization
}

\author{
Amandeep Singh \\ Department of Food Science and Technology, Guru Nanak Dev University, \\ Amritsar-143005 (Punjab), India \\ Varinder Kaur \\ Department of Chemistry, Guru Nanak Dev University, Amritsar-143005 (Punjab), India \\ R.S.S. Kaler* \\ Department of Food Science and Technology, Guru Nanak Dev University, \\ Amritsar-143005 (Punjab), India
}

${ }^{*}$ Corresponding author. E-mail: rsskaler@yahoo.com

\begin{abstract}
The consequence of food fiber has led to the expansion of a potential market for fiber-rich products and ingredients. Now days, research is being carried on novel resources of dietary fiber (DF), such as agronomic by-products which have traditionally been undervalued. The dietary fibers have its vital role in many physiological processes as well as in the avoidance of many ailments. However, dietary fibers have a number of scientific properties that can be applied in the formulation of foods resulting in surface modification and augmentation of the stability of the foods during their manufacturing and storage. There is a limited study on the effects of dietary fiber on vitamins. This signifies that less-fiber diets can increase the risk of ailment like colon cancer. The usage of fibers from new origins that are currently not fully exploited such as from bacteria, mosses, seaweeds, fruits and vegetables and the prospect of modifying the fibers joining them with other constituents and enhancing their nutritional and sensory attributes, would possibly broaden the field of application for dietary fibers. The present review assesses the classification, nutritional properties, physico-chemical properties and therapeutic functions of dietary fiber. The diets with the high intake of fiber are known to have positive effects on the health.
\end{abstract}

Keywords: Antioxidant, Cereals, Dietary fiber, Roasting

\section{INTRODUCTION}

Hipsley in 1953 was the first to use "dietary fiber" as a short hand term for the non suitable for eating constituents that make up the plant cell wall; It is generally supposed that these components were known to include cellulose, hemicelluloses, and lignin. Moreover "Dietary Fiber (DF) is a complex mixture of carbohydrates polymers that are associated with a number of other , noncarbohydrates components. The DF is predominantly found in plant cell walls and consists of non -starch polysaccharides (NSP) together with lignin, protein, fatty acids, waxes etc. (McDougall et al., 1996). The term "dietary fiber" was undoubtedly an effort to set apart some possessions or constituents of the foods. Wheat, barley, oat, rye, and maize are the cereals which are consumed as staple foods for the population of Western nations, contributing about $50 \%$ of dietary fiber (DF) intake. DF plays a significant role in many physiological processes and expectation of other diseases (Rodriguez et al., 2006). The expansion of fiber -enriched foods would facilitate consumers to fulfill such recommendations dietary fibers also have

\section{Article Info}

DOI:10.31018/jans.v10i4.1894 Received: September 15, 2018

Revised: November 30, 2018

Accepted: November 20, 2018

\section{How to Cite}

Singh, A. et al. (2018).

A review on dietary fiber in cereals and its characterization. Journal of Applied and Natural Science, 10 (4): $1216-1225$ scientific properties that can be used in the formulation of foods, resulting in surface modification and extension of the stability of the foodstuff during production and storage space (Thebaudin et al., 1997). Dietary fiber is that part of plant material which is mostly demanded by enzymatic absorption includes cellulose, non-cellulosic polysaccharides such as hemicelluloses, pectin's, gums, mucilage's and a non-carbohydrate component lignin. Mongeau (2003) classified DF into two categories with respect to their solubility in $\mathrm{H}_{2} \mathrm{O}$ : insoluble dietary fiber (IDF) such as cellulose, hemicellulose and lignin; and soluble dietary fiber (SDF) such as pentosans, pectins, gums and mucilages. Fiber rich diets for example cereals, nuts, fruits and vegetables have confirmatory effects on fitness since its consumption has been highly correlated to decreased frequency of numerous diseases. Dietary fiber can be used in a multiple functional foods such as bakery, drinks, beverages and meat products. DF can be determined by dissimilar methods, chiefly by enzymic gravimetric and enzymic chemical methods.

According to (Kay,1982) Botany scientists DF as a fraction of the plant organs whereas chemical an- 
alysts stated that it is a collection of chemical compounds whereas buyers as a substance with beneficial effects on personal physical fitness. "Dietary fiber is basically comprised of plant cells remains which cause hindrance to absorption by the alimentary enzymes of human", whose main components are hemicellulose, cellulose, lignin, oligosaccharides, pectins, gums and waxes (Trowell et al., 1985). Crude fiber is a measure of the quantity of indigestible cellulose, pentose and lignin and its fortitude is mostly used to approximate the superiority of plant origin and it constitutes their slightest digestible fiber fraction. Therefore, it is a decisive factor for evaluating fiber methods is the revitalization of indigestible plant remains. The significance of food fiber escorts expansion of the potential market for fiber rich foodstuffs and ingredients. In today scenario, there is a flow towards novel resources such as agronomic by-products that have conventionally well known for its worth (Mongeau and Brassard,1982).

According to American journal of clinical nutrition, crude fiber is the residue of plant food left subsequent extraction by dilute acid goes after by dilute alkali". American Association of Cereal Chemists (AACC) in 2000 defined DF as the edible portion of plant or analogous carbohydrates which confront digestion and absorption in the human small intestine with absolute or limited fermentation in the large intestine. Further Australia New Zealand Food Authority (ANZFA) define DF as a part of edible portion of plants and its extracts, and its relating carbohydrates, which is challenging to assimilation in the human small intestine whereas full or partial fermentation in the large intestine takes place. It includes polysaccharides, oligosaccharides and lignins. The board on the definition of dietary fiber proposed that cellulose, hemicellulose and lignin are not soluble in water while the pectins, gums and mucilages are insoluble in water. Dietary fiber is considered as a precious functional food, i.e a food with health benefits in numerous situations. It is beneficial for well being and illness avoidance have been well verified (Jalili et al., 2000; Topping et al.,1990).

Classification of dietary fiber: Dietary Fiber has various classifications that categorize the elements of DF based on their function in the plant and form of polysaccharide. The solubility of gastric juices, point of absorption is based on products of absorption and physiological classification (Tungland and Meyer, 2002). The most appropriately dietary fiber is classified into two categories such as water-insoluble known as least fermented fibers. For instance: cellulose, hemicellulose, lignin and the water-soluble called as well fermented fibers for example: pectin, gums and mucilages (Anita and Abraham, 1997). Cellulose, hemicellulose, and lignin are strongly intermeshed and chemically bonded by non-covalent forces and by covalent cross-linkage. Molecular genetics of cellulose, hemicelluloses and lignin-degrading systems advanced considerably during the 1990 (Pérez et al. 2002). Table 1 describes the classification of Dietary fiber found in their water solubility characteristics.

Cellulose: Cellulose is major cell wall constituent in plants; moreover it is un-branched linear sequence of numerous thousand glucose units with $\beta-1,4$ glucosidic linkages. Aspinall (1970) reported that cellulose is insoluble in strong alkali. The $(10-15 \%)$ quantity of cellulose, referred to "amorphous", it is willingly hydrolyzed by acid. Cellulose cannot absorb to any amount by the enzymes of the individual intestinal system. Cellulose makes up about $45 \%$ of the dry weight of wood. This linear polymer is composed of $D$ glucose subunits linked by b-1,4 glycosidic bonds forming cellobiose molecules. Cellulose can appear in crystalline form, called crystalline cellulose. In addition, there is a small percentage of non-organized cellulose chains, which form amorphous cellulose (Pérez et al., 2002).

Hemicellulose: These are polysaccharides present in cell wall. After removal of water soluble polysaccharides it may solubilized by aqueous alkali. It hold backbones of glucose units with $\beta-1$, 4 glucose linkages, quite be different from cellulose in the sense that they are miniature in size, hold diversity of sugars (xylose, glucose, fructose and sucrose) and is characteristically divided (Kay, 1982). Hemicellulose is a complex carbohydrate polymer and makes up $25-30 \%$ of total wood dry weight. It is a polysaccharide with a lower molecular weight than cellulose. It consists of $D$ -xylose, D-mannose, D-galactose, D-glucose, Larabinose, 4-O-methyl-glucuronic, D-galacturonic and D-glucouronic acids (Pérez et al., 2002).

Lignin: It is a complex polymer containing approximately forty oxygenated phenylpropane units as well as a complex dehydrogenative polymers (Theander and Aman 1979). Due to its important intramolecular bonding, it comprises CarbonCarbon linkages, lignin is mostly stationary i.e the reason that lignins sometimes vary in their molecular weight and methoxyl value. Lignin is, after cellulose, the second most abundant terrestrial biopolymer, accounting for approximately $30 \%$ of the organic carbon in the biosphere. The ability to synthesize lignin has been essential in the evolutionary adaptation of plants from an aquatic environment to land (Boerjan et al., 2003).

Pectin: It is a substance which is a complex of polysaccharides in which D-galacturonic acid is a principle component. They are structural portions of plant cell walls. They proceed as intercellular cementing substances. Pectin is frequently soluble in $\mathrm{H}_{2} \mathrm{O}$ and is totally metabolized by microorganisms. Because of its gelling behavior, such 
Table 1. Classification of dietary fiber found in their water solubility characteristics.

\begin{tabular}{|c|c|c|c|}
\hline Characteristics & Type of fiber & Explanation & Major Food resources \\
\hline \multirow[t]{3}{*}{ Water insoluble } & Cellulose & $\begin{array}{l}\text { Major structural part of plant cell wall, insoluble } \\
\text { in alkali and soluble in acid. }\end{array}$ & $\begin{array}{l}\text { Plants (vegetables and } \\
\text { various bran) }\end{array}$ \\
\hline & Hemicellulose & $\begin{array}{l}\text { Cell wall polysaccharides, Contains } \beta-1,4 \\
\text { glucosidic linkages, Soluble in dilute alkali. }\end{array}$ & Grains of cereals \\
\hline & Lignin & $\begin{array}{l}\text { Non-carbohydrate cell wall component, } \\
\text { challenging to bacterial deprivation. }\end{array}$ & Woody plants \\
\hline \multirow[t]{3}{*}{ Water soluble } & Pectin & $\begin{array}{l}\text { Constituents of main cell wall, soluble in } \mathrm{H}_{2} \mathrm{O} \\
\text { and gel forming. }\end{array}$ & $\begin{array}{l}\text { Fruits, vegetables and } \\
\text { legumes }\end{array}$ \\
\hline & Gums & $\begin{array}{l}\text { Mostly secreted at site of plant Injury, used in } \\
\text { foods and pharmaceuticals }\end{array}$ & $\begin{array}{l}\text { legume plants, sea- } \\
\text { weed extracts, gums }\end{array}$ \\
\hline & Mucilages & $\begin{array}{l}\text { Synthesized by plants, used in food industry } \\
\text { and hydroplilic stabilizer }\end{array}$ & $\begin{array}{l}\text { Plant extracts such as } \\
\text { gums }\end{array}$ \\
\hline
\end{tabular}

(Dhingra et al., 2012)

Table 2. Functions and benefits of dietary fiber based on human health characteristics.

\begin{tabular}{ll}
\hline Functions & Benefits \\
\hline Balance intestinal pH and stimulates & Lessens menace of Colorectal malignancy \\
$\begin{array}{l}\text { Lowers cholesterol level } \\
\text { Regulates blood pressure }\end{array}$ & $\begin{array}{l}\text { Danger of heart problems reduced } \\
\text { Reduce risk of metabolic syndrome and Diabetes to much } \\
\text { extent }\end{array}$ \\
$\begin{array}{ll}\text { Adjoin bulk to stools } & \text { Reduce troubles related to constipation } \\
\text { Add volume to diet, making feels stronger } & \text { Decrease hunger } \\
\text { Attracts water and turns to gel during } & \text { Subordinate inconsistency in blood sugar levels } \\
\text { absorption and losing assimilation of glucose } & \end{array}$ \\
\hline
\end{tabular}

(Dhingra et al., 2012)

soluble polysaccharides can lessens the pace of gastric emptying and authorize to modest level on intestinal transit time (Jenkins et al., 1978). Pectin is a major component of primary cell walls of all land plants and encompasses a range of galacturonic acid-rich polysaccharides. Three major pectic polysaccharides (homogalacturonan, rhamnogalacturonan-I and rhamnogalacturonan-II) are thought to occur in all primary cell walls (Willats et al., 2001).

Gums and mucilages: These are that categories of plant fibers which are not a portion of cell wall components and formed in specialized secretary plant cells These are reported to be highly branched polysaccharides that configure out gels from bound water and organic materials (Van Denffer et al., 1976). Sticky gum exudations create response to sufferings from gum arabic. Mucilages ooze into the endosperm of plant stones where they behave to stay apart from dehydration. Gums are considered to be pathological products formed following injury to the plant or owing to unfavorable conditions, such as drought, by a breakdown of cell walls (extra cellular formation; gummosis) while, mucilages are generally normal products of metabolism, formed within the cell (intracellular formation) and/or are produced without injury to the plant. Gums readily dissolve in water, whereas, mucilage form slimy masses (Jani et al., 2009).

Effects of eating too much/too less fiber: Intake of the high amount of fiber can cause numerous health troubles. Some have uncomfortable side effects while others can lead to further severe fitness issues (Slavin, 2013). Fiber is a natural substance found in fruits, vegetables and cereal grains and these are an essential part of the diet of a healthy body (Anderson et al., 2009). Moreover, fiber adds bulk to your diet, making you feel fuller faster and longer. It assists in digestion and be able to pass up the constipation. Too high amount intake of fibre results in Cramping, Diarrhoea, Malabsorption, Constipation, Intestinal gas and Intestinal blockage (Talley, 2006).

The risks of taking very less amount of fiber are Constipation, High Blood Pressure, Diabetes, Cardiovascular illness, Obesity, Malignancy (Anderson, 2009). It is important to consume adequate fiber on a regular basis to sustain health and vitality. Unluckily, most human beings don't even come close to intake the 20 to $25 \mathrm{~g}$ of fiber per day recommended by the American Dietetic Association (Shulman, 2010). Although fiber can be added to the diet by taking supplements, which is finest to attain it by eating a healthy diet consisting of ample of fruits, vegetables and whole cereal grains (Kushi, 2012).

Dietary fiber content in foods and its consumption: Dietary fiber is a combination of chemically assorted substances such as celluloses, hemicelluloses, pectins, lignins, gums and polysaccharides like seaweeds or bacteria but do not consist of a defined chemical group (Thebaudin et al., 1997). Cereals, vegetables, fruits and nuts naturally comprised with dietary fiber. Healthy adults should consume between 20 
to $35 \mathrm{~g}$ of dietary fiber daily which is suggested by experts whereas non-starch foods mostly provide upto $20-35 \mathrm{~g}$ of fiber per $100 \mathrm{~g}$ (Selvendran and Robertson (1994); Lambo et al., in (2005) reported that cereals are main sources of dietary fiber which contribute about $50 \%$ of the fiber intake in overseas. $30-40 \%$ DF attained from vegetables, approximately $16 \%$ from fruits and $3 \%$ from another sources. Arabinoxylans and (1/3)(1/4)- $\beta$-Dglucans are the main non-starch polysaccharides present diversely in wheat, barley and oat. The structural and physico-chemical properties of arabinoxylans manipulate its functions in manufacturing of products. Water-extractable arabinoxylans is highly sticky in hydrous solutions, whereas water-unextractable arabinoxylans generally practice strong water-holding capacity.

Furthermore, everyone should know about that range of molecular weight reported for $\beta$-glucans exemplify unevenness among cereals and oat $\beta$ glucans which mostly have higher molecular mass as compare to barley (Brennan and Cleary, 2005). The molecular weight of the glucans has notable results on product's viscosity which may effects end-use potential. One more stimulating constituent which is not commonly extracted from cereals but widely used as dietary fiber in diversity of foods is inulin. Inulin is a polydisperse fructan primarily comprise of $D$-fructose joined by $\beta-(2-1)$ linkages (Colleoni-Sirghie et al., 2003).

\section{Nutritional properties of dietary fiber}

Dietary fibers and cancers: Benefits of a diet rich in fiber are commonly have been discussed in past years. The unspecified protecting function of high fiber ingestion against cancer was strongly supported by Burkitt (1975). Burkitt and other researchers suggested that local people of Africa had a less occurrence of colon cancer as they consumed fiber-rich diets. There are a lot of troubles which estimates epidemiological studies of colon cancer, so there are several micronutrients in fruits and vegetables (vitamin $C, E$ and $\beta$ carotene), which are associated with a high-fiber diet, that have protective against cancer. It is also promising factor that some of the clear defensive outcomes from foods obtained from plant origin may be due to an inverse association of their intake with that of meat and animal fat. Trock et al. (1990) and other researchers evaluate numerous case studies and found a strong protective effect for dietary fruit and vegetables, but this may not attribute the effect to fiber. Insoluble fibers such as wheat bran can increase faecal bulk and dilute its contents, which decrease interactions into the intestinal mucosa and any carcinogens available in the faecal matter. Moreover, insoluble fiber diminishes intestinal transit times; permit handful opportunities for faecal mutagens to compare within intestinal epithelium.

Dietary fibers and protein metabolism: Studies on Protein metabolism have revealed that an improved nutritional fiber intake is associated with an increased nitrogen loss in faeces (Breslau et al., 1988). The nitrogenous substance is principally composed of bacterial origin and faecal mass improvement can expose bacterial increase on highfiber diets (Metzler et al., 2008). Time of digestion alters for proteins and the wholeness of absorption could have noteworthy suggestions for the use of high-fiber diets (David, 2011). Though, in recent studies it appears reasonably evidenced that dietary fiber manipulates absorption as well as assimilation of proteins.

Dietary fibres and intestinal transit time: Generally problem of constipation can be treated by intake of fiber rich diet. The physiological consequences are dependent on the types of dietary fibers, either insoluble or soluble (Galisteo et al., 2008). Insoluble fiber such as wheat bran and cellulose, add bulk to stool, make softer faeces, lift up faecal bulk and reduce intestinal transit time (Cummings, 2001). The water-holding capacity of fiber is important in clearing up the faecal-bulk. The increased faecal weight is usually attributed for increasing bacterial cell mass, non-digestible fiber remains and faecal water (Salminen et al., 1998). Fiber effect on faecal weight varies with the category and resource and occasionally with the practice on research of the foodstuffs. Fiber from cereals is more effective in increasing stool mass than fiber available from fruits. Soluble fibers like pectins not have any notable modification in colonic function or lowers intestinal transit time and mostly digestible by the human digestive system (Milton, 2003).

Dietary fibers and carbohydrate metabolism: Nutritional fibers have a negligible effect on carbohydrate metabolism, water-solvable fibers and foods loaded with sticky fibers have been initiated to reduce post prandial blood glucose levels. Such an act might be linked with viscosity (Jenkins, 1980).

Dietary fibers and mineral bioavailability: The concerns are that high fiber eating might well impair mineral incorporation due to chelating the minerals by means of dietary fibers (Gorinstein et al., 2001). Connections between minerals and fibers with varying chemical conditions make it hard to forecast the bioavailability of minerals. A good number on studied on minerals concerning interactions with dietary fiber include iron, zinc and calcium (Hunt, 2003). The results of fiber bioavailability of minerals depend basically on the category of fiber consumed. Fiber from wheat bran supply mostly used in experimentations. Studies have revealed a damaging effect of wheat and corn cereal fibers on iron and zinc absorption in both animals and human beings. Various fiber ingredients such as guar gum, lignin and psyllium husk have inhibitory consequences on iron absorption 
(Chawla et al., 2010). Several studies exposed that dietary fibers never hold back iron or zinc absorption. The elimination of phytate has been revealed to obtain improved bioavailability of iron, zinc, calcium and phytate can be removed during the processing of fiber ingredients. Research has also indicated that wheat fiber compact calcium assimilation in both animals and humans.

Dietary fiber for antioxidants capacity: Sufficient every day eating of dietary fiber (DF) and antioxidants generate considerable consequences in the interference of chronic diseases (SauraCalixto et al., 2010). Frequent in-vitro in-vivo studies introduce the role of DF in intestinal health, cancer, obesity and diabetes. Dietary antioxidant capacity can be defined as the Antioxidant Capacity (AOC) of all foods obtained from plants and beverages whether alcoholic and non-alcholic, consumed daily in the diet (Cencic and Chingwaru 2010). This parameter represents the number of antioxidant units' equivalent to Trolox which should present daily in the human gut.

Dietary fibers and vitamin bioavailability: Dietary fiber intake enhances vitamin absorption by stimulating enzymes and bile secretion by rising in transit time (Lattimer and Haub, 2010). Several foods comprise inhibitors of vitamin consumption which lowers release time. Inhibitor proteases are there in several raw fruits and vegetables which may influence vitamin inclusion, such as substances can decrease bile salts absorption. Inspite of this inadequate work has been carried out on the effects of dietary fibers on vitamin bioavailability, so vitamins $E$ and $D$ acknowledged more consideration (Fernandez-Garcia, 2012). The effects of numerous diverse types of dietary fiber on vitamin $E$ class were investigated. They originate that rats fed crude wheat bran had inferior hepatic a-toccopherol levels than rats fed ground wheat bran or cellulose, and terminated that coarse bran decreased toccopherol bioavailability. Studies have shown that a high-fiber diet can lead to the enhanced elimination of vitamin $D$. This may incompletely make apparent that the low vitamin D status noticed in vegetarians.

Dietary fibers and lipid metabolism: Lipid metabolism in dietary fiber was largely studied in a recent evaluation on soluble fiber and serum lipids. Glore et al., (1994) point toward that the mainstream of verification to soluble fiber having the probable to inferior the levels of whole cholesterol and small density lipoprotein cholesterol in the serum. Investigation shows that addition of bile salts by dietary fiber may change significantly in cholesterol metabolism; however it leads to the beating of cholesterol from the body (Nair et al., 2010). Bile acid secretion would require improved synthesis of bile acids from cholesterol. Moreover, the unavailability of bile salts in the intestine for micelle formation would also restrain lipid and cholesterol absorption (Sinha et al., 2011). Dietary fibers, like barley and sugar beet, have been disclosed to increase faecal bulk and thereby dilute bile acids in the lower tract of the intestine. The occurrence of bacterial fermentation of dietary fibers could contribute to lipid metabolism.

Technological and functional properties of dietary fiber

Hydration and oil binding properties: The hydration properties of dietary fibers wrap up their most positive usage in foods because of a pleasant consistency (Cushen et al., 2012). The hydration properties are described by various measurable parameters i.e water-absorption capacity (WAC), water-binding capacity (WBC), swelling and solubility (Azad, 2003). Hydration properties of dietary fibers are associated with the substantial arrangement of the polysaccharides and other factors like porosity, particle size, ionic form, level of $\mathrm{pH}$, and temperature. Moreover ionic strength and pressure upon fibers are also dependable factors (Tudorica, 2002). The viewpoint of fibers to bound water is mostly related to the storage of the dietary fibers. Dietary fibers from algal sources named Laminaria digitata cover enhanced connection for water and oil than those from fruit juice by-products. By-products from cereals have the lowest similarity; these differences are linked to the chemical properties of the fibers and upon its hydration properties. Fleury and Lahaye (1991) reported that enhancement in $\mathrm{H}_{2} \mathrm{O}$ increase with the rise in temperature is possibly related to improvement in the soluble nature of fibers.

Mostly Fibers have a capability to bound oil. Oil Absorption Capacity (OAC) is the extent of oil trapped by the fibers upon mixing followed by incubation and centrifugation. Caprez et al., in 1986 reported that absorption of oil in cereal products such as wheat bran is principally linked to the peripheral properties of the bran specks but might be related to the whole charge density as well as to the hydrophilic nature of the elements. Alginate and Fucan from the algal source are main evidences (Fleury and Lahaye, 1991). Water holding capacity (WHC), Swelling Power (SP) and Oil Absorption Capacity (OAC) suggest some potential upon use of fibers as ingredients in food products. Dietary fibers with high OAC allows the stabilization of extra fatty foodstuffs and emulsions. Dietary fibers with high WAC may be used as functional ingredients to evade syneresis and regulate the viscosity and quality of various formulated foods (Grigelmo-Miguel and Martina-Belloso, 1999).

Texture and stabilizing properties: Textural and stabilizing properties result from the hydration properties of the fibers. The additions of dietary fibers into foods convert the consistency and solidity of the processing (Singh, 2017). The methods may vary accordingly. The thickening of xan- 
than and locust-bean gums and gelling of carrageenans, pectins and the water-retention capacity contribute to the stabilization of the composition of foods in dispersions, emulsions and foams by converting the rheological properties of the continuous phase (Banerjee and Bhattacharya 2012). Owing to their water-retention ability and swelling properties, insoluble fibers can influence food texture. It is property which cannot be directly appraised by mechanical measures i.e by penetrometric measures. The influences of particle size and origin of dietary fibers on the firmness of apple and sugar-beet fibers disclose better inflexibility than wheat-bran fiber (Thebaudin et al., 1997).

Antioxidant properties: Non-starch polysaccharides exhibits antioxidant properties and probably developed as potential antioxidants (Elleuch et al., 2011). Various polysaccharide fractions obtained from rice bran recommend protection next to the superoxide radical, hydroxyl liberated radical, lipid oxidation and reveal the excellent potential for reducing power and chelating ferrous ions (Butsat et al., 2009).The leading scavenging potential upon a hydroxyl radical about $96.3 \%$ was attained by polysaccharides extracted by way of boiledwater from rice bran by precipitated it with $40 \%$ ethanol with the concentration of $1.0 \mathrm{mg} / \mathrm{ml}$. It was competent as compared to ascorbic acid (Zha et al., 2009). Some suggestions are promising for use of fibers throughout elevated antioxidant activities such as ingredients that allow the stabilization of fatty foods and ultimately improve their oxidative stability by prolonging their shelf life. Such high fiber products have many technological properties like water holding capacity, water swelling capacity, water-solubility index, fat binding capacity, viscosity and antioxidant properties that may justify its consumption in ingredients in food sector.

Remedial functions of dietary fiber: Cereals, fruits and vegetables rich in fiber have a confirmatory effect upon their utilization. It has been related to a reduced incidence of many types of illness due to its positive effects such as an increase in feacal mass by declining the moment of intestinal transit and cholesterol level (Rodriguez et al., 2006). Moreover, glycaemic index and propagation of the intestinal flora will initiate etc (Heredia et al., 2002; Beecher 1999). Various purposes and paybacks of DF on a person's health are detailed in Table 2. It was proposed that the DF act as a defensive factor in tumor resulting decrease the time for arrangement and action of carcinogens. Through its stool-bulking factor, it may reduce the reflection of feacal carcinogens (Hill 1974; Burkitt 1975). Graham et al. (1978) reported that the ingestion of certain vegetables enriched in fiber was inversely correlated with the occurrence of cancer. Developments in diabetic management and a decline in insulin supplies reported that mild and modest diabetes on high fiber diets containing a regular or elevated quantity of carbohydrates (Dhingra et al., 2012). Pectin, guar gum and gum- arabic as well demonstrate a hypolipidic results in humans (Kay and Truswell 1977). Walker (1974) reported in his study of the diet of people from South Africa on comparison basis and instigate that the native population of Africa consumed non-refined corn flour with a higher percentage of fiber. There are lower chances of diseases like atherosclerosis and colon cancer which has its high incidence among other population of western countries. Foods that are loaded with fiber grasp a broad field of compounds that can reduce the incidence of different types of cancer. Similar results have been reported by Kritchersky (1990) and Trowell (1976). Dietary fiber plays a significant role in avoidance of so many diseases resulting by taking diets with a higher level of fiber content; Cereals and cereal fiber have optimistic effects on health (Beecher 1999; Saura-Calixto et al., 2010). Fiber from plant sources controls the intestinal transit time through its own action on the faecal matter. It creates an effect on carbohydrate and lipid metabolism which is typically related to components like flavonoids and carotenoids. Such components are supportive for strength and fitness of human beings (Heredia et al., 2002 and Thebaudin and Lefebvre, 1997).

Dietary fiber in functional foods: Nutrients which effect positively on precise organic functions, civilizing health and reduce the hazard of different diseases are known as Functional Foods (Diplock et al., 1999). The International Life Science Institute (ILSI Europe) in 1999 recognized that "a food product may consider as functional if it has been confirmed that it produces a valuable effect on one or more physiological functions. The consequences of food fibers lead to the development of immense latent advertise for fiber laden foodstuffs. In today's scenario there is a drift to come across novel resources of dietary fiber that can be used for its varied functionality in the food production (Chau and Huang, 2003). The addition of DF to bakery goods improves their dietetic worth as it makes possible to reduce the risk of obesity. DF can use as an alternate of fat without loss of quality attributes (Byrne, 1997). DF based on pectin, cellulose, soy, wheat, corn or rice isolates and root beet fiber is used for civilizing the uniformity of meat products such as sausages and salami. At the same time such fibers are efficient to make low-fat products like 'dietetic hamburgers' reported that fiber can also be created from the sources that might be measured as waste products. For instance; Straw from wheat, soya hull, oat hull, corn cobs along with stalks transformed into fiber components, which can be incorporated in particular food applications. Among foods that are rich in fiber largely consumed in mealtime ce- 
reals and baked goods such as vital breads and cookies (Cho and Prosky, 1999; Nelson 2001). In the manufacturing of baked goods, addition of fiber rich ingredients increase the water hydration standards of flour used in baked goods. Toma et al., (1979) informed that the bread baked along with potato skin as a substitute of wheat bran gives superior results in the terms of availability of minerals.

The adding up of dietary fiber to baked products might also develops their dietetic excellence since it makes promising feature to reduce the fat by using dietary fiber as alternate of fat with no quality reduction. Supplementation of rice fiber considerably enhanced the dietary fiber content, mineral and protein content of the cookies. Oat fiber can be included into milk shakes, ready-to-serve breakfast drinks, juices, ice tea, nutritional drinks and wine. Soluble fibers such as pectins, inulin, guar gum and Carboxy Methyl Cellulose used as useful ingredients in the milk based commodities (Nelson 2001). Fermented milk products supplemented with fiber from citrus sources has outstanding outcomes to nourish immunity in humans.

Effect of processing on the dietary fiber: The physio-chemical properties of fiber are capable to manipulate throughout the treatment like chemical, enzymatic, mechanical and thermal properties to increase its functionality (Guillon and Champ, 2000). Grinding of fiber may interfere with the water holding properties, particularly the kinetics of water uptake as the significant in the enlarged surface area, resulting the fibers hydrate in very short span. Upon Heating fibers commonly modified with the ratio of soluble to insoluble fiber. Mixture of both thermal and mechanical energy can considerably alter the composition of dietary fiber at all structural phases leads to novel functional properties (Spiller, 1986; Roehrig, 1988). In wheat fiber it formerly invent that thermal treatments such as boiling, cooking or roasting may increase total fiber. Some changes will take place in thermally processed kidney beans and said that solubilization of the polysaccharides ended up in decreasing TDF content, which is majorly due to loss of soluble fiber upon cooking, boiling and frying (Caprez et al., 1986). Varo et al., (1983) in diverse lab studies reported that using different analytical methods, the treated potato samples with high temperature contain extra water insoluble DF and low starch than uncooked samples. No any of modifications noticed in the whole dietary fibers and starch in the extruded samples. Herranz et al., (1983) studied about nature of different fibers such as NDF, ADF, cellulose, hemicelluloses and lignin percentage of freeze and canned vegetables and observed that heating resulted in increase the NDF, ADF and cellulose percentages. An unimportant increase in hemicelluloses and nothing change in lignin samples were noticed. The effect of household cooking on dietary fiber and starch composition of processed potatoes products were assessed and resulted that microwave heating have profound effects on oil frying which lessens its substantial quantity if in-vitro digestible starch and significantly increases were noticed in both the resistant starch and waterinsoluble dietary fiber. Thed and Phillips (1995) reported that water-soluble dietary fiber content was being not affected by none of the domestic food preparation methods. Camire et al. (1997) also accepted a number of revisions on distinctions in the dietary fiber composition of potato peels as affected by diverse methods of peelings such as abrasion, steam peeling and extrusion cooking

\section{Conclusion}

Several studies authenticate the dietetic benefits of dietary fibers. However sometimes it is difficult to express firm conclusions since different sources and composition (soluble or insoluble) of fibers experienced moreover it depends upon the outcomes. Insoluble dietary fibers improve intestinal passage hours. Dietary fibers obtained from cereals have been reported to decrease zinc, iron and calcium absorption, but this effect may be due to the incident of other components in fibers, like phytate. The trends signify that high-fiber diets can decrease the hazards of colon cancer. The range of structure and composition of dietary fibers make it difficult for their mechanisms of action. The usage of fibers from novel origins is currently not fully exploited such as from bacteria, mosses, seaweeds, fruits, vegetables etc. The prospect of modifying the fibers joining them with other constituents and enhancing their nutritional and sensory attributes, would possibly broadens the field of application for dietary fibers. For example, the action of cereal bran, vegetable or fruit pulp with an alkaline solution of hydrogen peroxide eradicates part of the lignin and enhances the water absorption capacity of the resulting fibers. The diets with high fiber intake will have positive effects on physical strength. The inclusion of fiber can change some prospects like consistency, texture, rheology and sensory attributes of the finished products. Fiber in breakfast cereals like bread, cookies, cakes, yogurt, beverages and animal protein products may have outstanding wellbeing outcomes.

\section{REFERENCES}

1. Anderson, J. W., Baird, P., Davis, R. H., Ferreri, S., Knudtson, M., Koraym, A. and Williams, C. L. (2009). Health benefits of dietary fiber. Nutrition Reviews, 67: 188-205.

2. Anita, F.P. and Abraham, P.(1997). Clinical dietetics and nutrition. Oxford University Press, Calcutta, pp 73-77 
3. Aspinall, G.O. (1970). Analysis of Toxic Extracellular Polysaccharides. Pergamon Press, Oxford, pp 130144

4. Azad Azaz Ahmad, Z. R. (2003). Effects of Treatments, Packaging Materials and Storage Conditions on Physico-Chemical Characteristics and Shelf-Life of Buffalo Meat (Doctoral dissertation, Aligarh Muslim University)

5. Banerjee, S., and Bhattacharya, S. (2012). Food gels: gelling process and new applications. Critical Reviews in Food Science and Nutrition, 52: 334-346.

6. Beecher, G.R. (1999). Phytonutrients role in metabolism: effects on resistance to degenerative processes, Nutritional Review, 57: 3-6

7. Boerjan, W., Ralph, J., and Baucher, M. (2003). Lignin biosynthesis. Annual review of Plant Biology, 54: 519-546.

8. Brennan, C. S., and Cleary, L. J. (2005). The potential use of cereal $(1 \rightarrow 3,1 \rightarrow 4)-\beta$-D-glucans as functional food ingredients. Journal of Cereal Science, 42: 1-13.

9. Breslau, N. A., Brinkley, L., Hill, K. D., and PAK, C. Y. (1988). Relationship of animal protein-rich diet to kidney stone formation and calcium metabolism. The Journal of Clinical Endocrinology and Metabolism, 66:140-146.

10.Burkitt, D.P. (1975) Large-bowel cancer: an epidemiological jigsaw puzzle. J. National Cancer Institute, 54: 3-6

11.Butsat, S., Weerapreeyakul, N., and Siriamornpun, S. (2009). Changes in phenolic acids and antioxidant activity in Thai rice husk at five growth stages during grain development. Journal of agricultural and food chemistry, 57: 4566-4571.

12.Byrne, M. (1997). Low-fat with taste. Food Engineering International, 22: 36-41

13.Camire, M. E., Violette, D., Dougherty, M. P., and McLaughlin, M. A. (1997). Potato peel dietary fiber composition: effects of peeling and extrusion cooking processes. Journal of Agricultural and Food Chemistry, 45: 1404-1408.

14.Caprez, A., Arrigoni, E., Amado, R., and Zeukom, H. (1986). Influence of different types of thermal treatment on the chemical composition and physical properties of wheat bran. Journal of Cereal Science, 4: 233-239.

15.Cencic, A., and Chingwaru, W. (2010). The role of functional foods, nutraceuticals, and food supplements in intestinal health. Nutrients, 2: 611-625.

16.Chau, C.F., and Huang, Y. L. (2003). Comparison of the chemical composition and physicochemical properties of different fibers prepared from peel of Citrus sinensis L. Cv. Liucheng. Journal of Agricultural and Food Chemistry, 51: 2615-2618

17.Chawla, R. P. G. R., and Patil, G. R., (2010). Soluble dietary fiber. Comprehensive Reviews in Food Science and Food Safety, 9: 178-196.

18.Cho, S.S., and Prosky, L., (1999). Application of complex carbohydrates to food product fat mimetics. Complex Carbohydrates in Foods, (pp. 411-430). New York: Marcel Dekker

19.Colleoni-Sirghie, M., Fulton, D. B., \& White, P. J. (2003). Structural features of water soluble $(1,3)(1$, $4)-\beta$ - $D$-glucans from high- $\beta$-glucan and traditional oat lines. Carbohydrate Polymers, 54: 237-249.

20.Cummings, J. H. (2001). The effect of dietary fiber on fecal weight and composition. CRC Handbook of
Dietary Fiber in Human Nutrition, 3: 183-252.

21.Cushen, M., Kerry, J., Morris, M., Cruz-Romero, M., and Cummins, E. (2012). Nanotechnologies in the food industry-Recent developments, risks and regulation. Trends in Food Science \& Technology, 24:3046

22.David, M. (2011). Nourishing wisdom: A mind-body approach to nutrition and well-being. Harmony.

23.Dhingra, D., Michael, M., Rajput, H., and Patil, R. T. (2012). Dietary fibre in foods: a review. Journal of Food Science and Technology, 49: 255-266

24.Diplock, A. T., Aggett, P. J., Ashwell, M., Bornet, F., Fern, E. B., and Roberfroid, M. B. (1999). Scientific concepts of functional foods in Europe: Consensus document. British Journal of Nutrition, 81: 1-27

25.Elleuch, M., Bedigian, D., Roiseux, O., Besbes, S., Blecker, C., and Attia, H. (2011). Dietary fibre and fibre-rich by-products of food processing: Characterisation, technological functionality and commercial applications: A review. Food chemistry, 124:411-421

26.Fernandez-Garcia, E., Carvajal-Lerida, I., JarenGalan, M., Garrido-Fernandez, J., Perez-Galvez, A., and Hornero-Mendez, D. (2012). Carotenoids bioavailability from foods: From plant pigments to efficient biological activities. Food Research International, 46 : 438-450.

27.Fleury, N., and Lahaye, M. (1991). Chemical and physico-chemical characterization of fibers from Lamiaria digitata (Kombu Breton): A physiological approach. Journal of the Science of Food and Agriculture, 55: 389-400

28.Galisteo, M., Duarte, J., and Zarzuelo, A. (2008). Effects of dietary fibers on disturbances clustered in the metabolic syndrome. The Journal of Nutritional Biochemistry, 19: 71-84.

29.Glore, S. R., Van Treeck, D., Knehans, A. W., and Guild, M. (1994). Soluble fiber and serum lipids: a literature review. Journal of the American Dietetic Association, 94: 425-436.

30.Gorinstein, S., Zachwieja, Z., Folta, M., Barton, H. Piotrowicz, J., Zemser, M., and Martin-Belloso, $\mathrm{O}$. (2001). Comparative contents of dietary fiber, total phenolics, and minerals in persimmons and apples. Journal of Agricultural and Food Chemistry, 49:952957

31.Graham S, Dayal H, Swanson M, Mittleman A, and Wilkinson G (1978) Diet in the epidemiology of cancer of the colon and rectum. J. Natl. Cancer Znst., 61: 709-714

32.Grigelmo-Miguel, N., Carreras-Boladeras, E., and Martin-Belloso, O. (1999). Development of high-fruitdietary-fibre muffins. European Food Research and Technology, 210: 123-128

33.Guillon, F., and Champ, M. (2000). Structural and physical properties of dietary fibres and consequences of processing on human physiology. Food Research International, 33: 233-245.

34. Heredia-Tapia, A., Arredondo-Vega, B. O., NunezVazquez, E. J., Yasumoto, T., Yasuda, M., and Ochoa, J. L. (2002). Isolation of Prorocentrum lima (Syn. Exuviaella lima) and diarrhetic shellfish poisoning (DSP) risk assessment in the Gulf of California, Mexico. Toxicon, 40: 1121-1127.

35.Herranz, J., Vidal-Valverde, N., and Rojas-Hidalgo, E. (1983). Cellulose, hemicellulose and lignin content of raw and cooked processed vegetables. Journal of Food Science, 48: 274-275. 
36. Hill, A. (1974). Experimental and natural infection of the conjunctiva of rats. Laboratory animals, 8:305310

37.Hipsley, E. H. (1953). Dietary "fiber" and pregnancy toxaemia. Brit. Med. J, 2: 411-420

38.Hunt, J. R. (2003). Bioavailability of iron, zinc, and other trace minerals from vegetarian diets. The American Journal of Clinical Nutrition, 78: 633-639.

39.Jalili, T., Wildman, R. E., and Medeiros, D. M. (2000). Nutraceutical roles of dietary fiber. Journal of Nutraceuticals, Functional \& Medical Foods, 2:19-34

40.Jani, G. K., Shah, D. P., Prajapati, V. D., and Jain, V. C. (2009). Gums and mucilages: versatile excipients for pharmaceutical formulations. Asian J. Pharm. Sci., 4: 309-323.

41.Jenkins, D. J. (1980). Dietary fiber and carbohydrate metabolism. In Medical aspects of dietary fiber (pp. 175-192). Springer, Boston, MA.

42.Jenkins, D.J.A., Wolever, T.M.S., Leeds, A.R., Gassull, M.A., Haisman, P., Dilawari, J., Goff, D.V., and Meta, G.L. (1978) Dietary fibres, fibre analogues and glucose tolerance: importance of viscosity. Br Med J., 1: 1392-1394

43.Kay, R. M. (1982). Dietary fiber. Journal of lipid research, 23: 221-242.

44.Kay, R. M. and Truswell, A. S. (1977). Effect of citrus pectin on blood lipids and fecal steroid excretion in man. The American journal of Clinical Nutrition, 30: 171-175.

45.Kritchersky, D. (1990). In I. Furda, and Ch. J. Brine, Dietary fiber. A glance into the future: New developments in dietary fiber (Vol. 3) (pp. 1-5). New York: Plenum Press

46.Kushi, L. H., Doyle, C., McCullough, M., Rock, C. L., Demark-Wahnefried, W., Bandera, E. V., and American Cancer Society 2010 Nutrition and Physical Activity Guidelines Advisory Committee. (2012). CA: A Cancer Journal for Clinicians, 62: 30-67.

47.Lambo, A. M., Oste, R., and Nyman, M. E. L. (2005). Dietary fiber in fermented oat and barley $\beta$-glucan rich concentrates. Food Chemistry, 89: 283-293.

48.Lattimer, J. M., and Haub, M. D. (2010). Effects of dietary fiber and its components on metabolic health. Nutrients, 2: 1266-1289.

49.McDougall, G. J., Morrison, I. M., Stewart, D., and Hillman, J. R. (1996). Plant cell walls as dietary fiber: range, structure, processing and function. Journal of the Science of Food and Agriculture, 70: 133-150.

50.Metzler, B. U., and Mosenthin, R. (2008). A review of interactions between dietary fiber and the gastrointestinal microbiota and their consequences on intestinal phosphorus metabolism in growing pigs. Asian Australasian Journal of Animal Sciences, 21:603-615

51.Milton, K. (2003). The critical role played by animal source foods in human (Homo) evolution. The Journal of Nutrition, 133: 3886-3892.

52.Mongeau, R. (2003). Dietary fiber. In R. Macrae, R. K. Robinson, M. J. Sadler (Eds.), Encyclopaedia of Food Science and Nutrition, (pp. 1362-1387). New York: Academic Press.

53.Mongeau, R., and Brassard, R. (1982). Determination of neutral detergent fiber in breakfast cereals: pentose, hemicellulose, cellulose and lignin content. Journal of Food Science, 47: 550-555.

54.Nair, H., Nokes, D. J., Gessner, B. D., Dherani, M., Madhi, S. A., Singleton, R. J., and Chandran, A. (2010). Global burden of acute lower respiratory in- fections due to respiratory syncytial virus in young children: a systematic review and meta-analysis. The Lancet, 375: 1545-1555.

55.Nelson, D. R. (2001). Compilation of geochronology data, 2000. Geological Survey of Western Australia.

56.Pérez, J., Munoz-Dorado, J., de la Rubia, T. D. L. R., and Martinez, J. (2002). Biodegradation and biological treatments of cellulose, hemicellulose and lignin: an overview. International Microbiology, 5: 53-63.

57.Rodriguez-Viciana, P., Tetsu, O., Tidyman, W. E., Estep, A. L., Conger, B. A., Santa Cruz, M., and Rauen, K. A. (2006). Germline mutations in genes within the MAPK pathway cause cardio-facio-cutaneous syndrome. Science, 311: 1287-1290.

58.Roehrig, K. L. (1988). The physiological effects of dietary fiber-a review. Food Hydrocolloids, 2: 1-18.

59.Salminen, S., Bouley, C., Boutron, M. C., Cummings, J. H., Franck, A., Gibson, G. R., and Rowland, I. (1998). Functional food science and gastrointestinal physiology and function. British Journal of Nutrition, 80: 147-171.

60.Saura-Calixto, F. (2010). Dietary fiber as a carrier of dietary antioxidants: an essential physiological function. Journal of Agricultural and Food Chemistry, 59: 43-49.

61.Selvendran, R. R., and Robertson, J. A. (1994). Dietary fibre in foods: amount and type. Metabolic and physiological aspects of dietary fibre in food. Commission of the European Communities, Luxembourg, 11-20.

62.Shulman, J. (2010). The Natural Makeover Diet: A 4step Program to Looking and Feeling You Best from the Inside Out. John Wiley and Sons.

63.Singh, K. (2017). "Studies on Effect of pretreatments on Quality Attributes of Guava" (Psidium guajava var. Allahabad safeda) (Doctoral dissertation, Sam Higginbottom University of Agriculture Technology and Sciences (Formerly Allahabad Agricultural Institute) Allahabad-211007).

64.Sinha, A. K., Kumar, V., Makkar, H. P., De Boeck, G., and Becker, K. (2011). Non-starch polysaccharides and their role in fish nutrition-A review. Food Chemistry, 127: 1409-1426.

65.Slavin, J. (2013). Fiber and prebiotics: mechanisms and health benefits. Nutrients, 5: 1417-1435.

66.Spiller, P. T., and Huang, C. J. (1986). On the extent of the market: wholesale gasoline in the northeastern United States. The Journal of Industrial Economics, 131-145.

67. Talley, N. J. (2006). Conquering irritable bowel syndrome: a guide to liberating those suffering with chronic stomach or bowel problems. PMPH-USA.

68. Theander, O., and Aman, P. (1979). Studies on dietary fibers, 1: Analysis and chemical characterization of water-soluble and water-insoluble dietary fibers [wheat bran, rye bran, rye biscuits, potatoes, carrots, peas, white cabbage, lettuce, apples]. Swedish Journal of Agricultural Research (Sweden).

69. Thebaudin J.Y., Lefebvre A.C., Harrington M. and Bourgeois C.M. (1997). Trends in Food Science and Technology, 81: 41- 47

70.Thed, S. T., and Phillips, R. D. (1995). Changes of dietary fiber and starch composition of processed potato products during domestic cooking. Food Chemistry, 52: 301-304.

71.Toma, R. B., Orr, P. H., D'appolonia, B., Dintzis, F. R., and Tabekhia, M. M. (1979). Physical and chemi- 
cal properties of potato peel as a source of dietary fiber in bread. Journal of Food Science, 44:14031407

72.Topping, D. L., Illman, R. J., Roach, P. D., Trimble, R. P., Kambouris, A., and Nestel, P. J. (1990). Modulation of the hypolipidemic effect of fish oils by dietary fiber in rats: studies with rice and wheat bran. The Journal of nutrition, 120: 325-330.

73.Trock, B., Lanza, E., and Greenwald, P. (1990). Dietary fiber, vegetables, and colon cancer: critical review and meta-analyses of the epidemiologic evidence. JNCl: Journal of the National Cancer Institute, 82: $650-661$

74.Trowell, H., Burkitt, D., and Heaton, K. (1985). Dietary fibre, fibre-depleted foods and disease. Trowell, H., Southgate, D. T., Wolever, T. S., Leeds, A., Gassull, M., and Jenkins, D. A. (1976). Dietary fiber redefined. The Lancet, 307: 967.

75.Tudorica, C. M., Kuri, V., and Brennan, C. S. (2002). Nutritional and physicochemical characteristics of dietary fiber enriched pasta. Journal of Agricultural and Food chemistry, 50: 347-356.
76.Tungland, B. C. and Meyer, D. (2002). Nondigestible oligo-and polysaccharides (Dietary Fiber): their physiology and role in human health and food. Comprehensive reviews in food science and food safety, 1: 90-109.

77.Van Denffer, D., Schumacher, W., Magdefrau, K., and Ehrendorfer, F. (1976). Excretory and secretory tissues. Strasbueger's textbook of botany. Longman, New York, 118-121.

78.Varo, P., Laine, R., and Koivistoinen, P. (1983). Effect of heat treatment of dietary fiber: interlaboratory study. Journal-Association of Official Analytical Chemists, 66: 933-938.

79.Willats, W. G., McCartney, L., Mackie, W., and Knox, J. P. (2001). Pectin: cell biology and prospects for functional analysis. Plant Molecular Biology, 47: 9-27.

80.Zha, X.Q., Wang, J.H., Yang, X.F., Liang, H., Zhao, L.L., and Bao, S. H. (2009). Antioxidant properties of polysaccharide fraction with different molecular mass extracted with hot-water from rice bran. Carbohydrate Polymers, 78: 570-575 